\title{
Culture and Social Resistance to Reform: A theory about the endogeneity of public beliefs with an application to the case of Argentina
}

\author{
Sergio Pernice \\ Universidad del CEMA \\ Federico Sturzenegger \\ Universidad Torcuato Di Tella \\ "Conflicts of interests dominate \\ the short run, but conflicts \\ of visions dominate history" \\ A Conflict of Visions, by Thomas Sowell
}

"Never underestimate the power of denial"

American Beauty

\section{Introduction}

This paper attempts to understand the factors that explain the degree of support or criticism that a reform process may be subject to. Understanding these determinants is critical, in turn, to assess the feasibility and sustainability of those reforms. In particular, we want to assess what are the elements that create societal consensus for reform and which are the main factors that turn public opinion against it. In the case of Argentina, for example, such dynamics are critical to understand how public opinion imposed constraints on government behavior, affected macroeconomic performance, and ultimately, determined the chance of success of reforms.

*The views and opinions expressed in this publication are those of the authors and are not necessarily those of the Universidad del CEMA. 


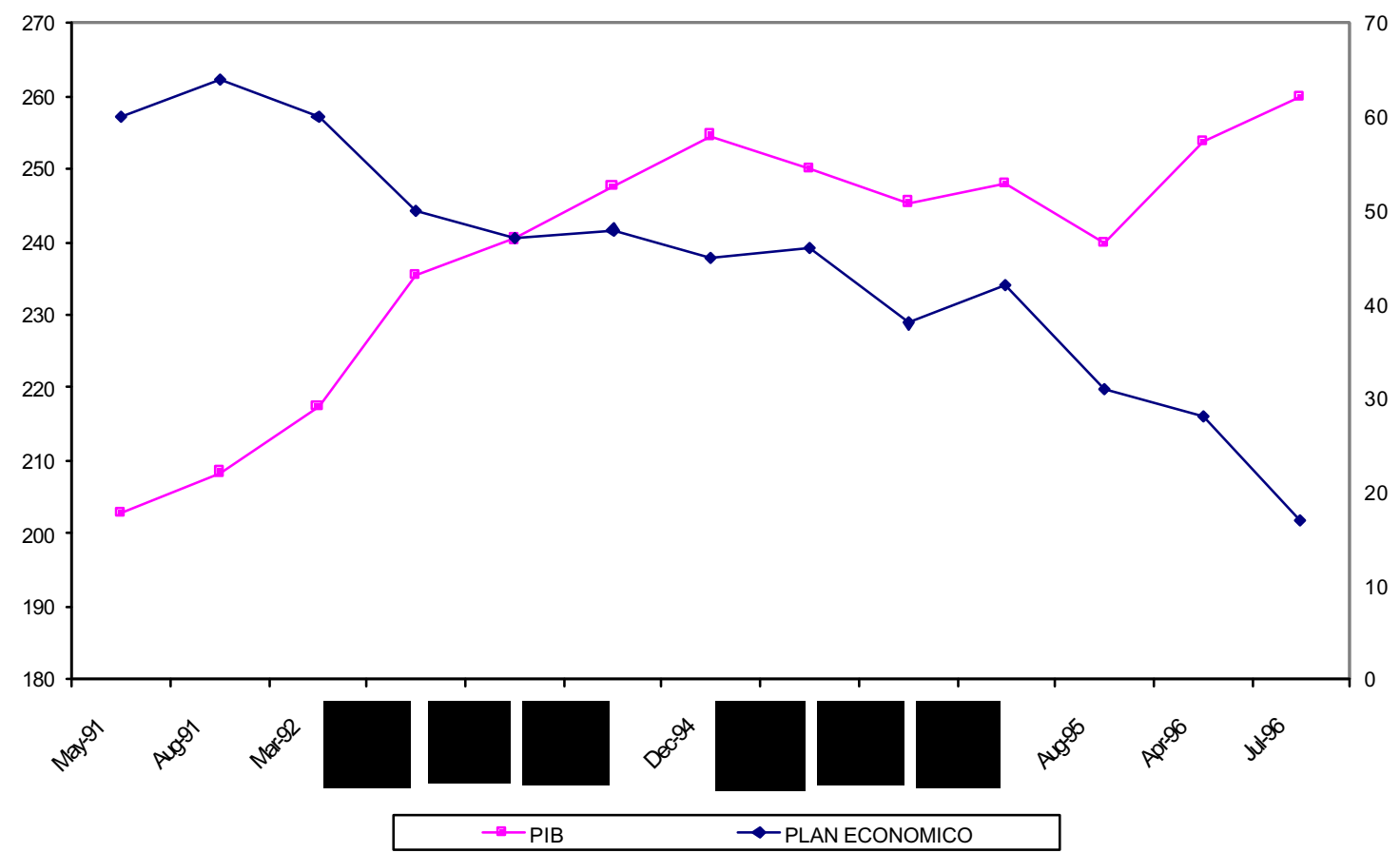

The reform process in Argentina started at the beginning of the 90s. As can be seen in the graph, this led to substantial economic growth, a stark contrast with the stagnation of the previous decade. Likewise, there was an initial reduction in the poverty rate, and the disappearance of the previously ubiquitous high inflation. From the perspective of basically any objective observer the Convertibility Plan before the Tequila crisis was a success.

Figure 1 shows the degree of support of the economic program throughout the first decade of this reform process. As can be seen, shortly after the implementation, public opinion turned sour.

Needless to say, the implementation of an economic plan that dramatically changes the patterns of economic organization that the country had been working upon during the previous fifty years is, of course, a complex phenomenon. This process affected the everyday life of every Argentineans in many ways. Therefore, as in every complex, realworld, politico-economical process, there are thousands of different aspects and angles from which such phenomenon can be interpreted.

However, the progressive decline of support shown in Figure 1 suggests that the public opinion was focusing in those aspects of the plan that were not working so well as, for example, the growth in the unemployment rate. Figure 2, which presents public perception 
about the principal problems that affected the country shows that, in fact, unemployment became "the problem" as soon as 1993.

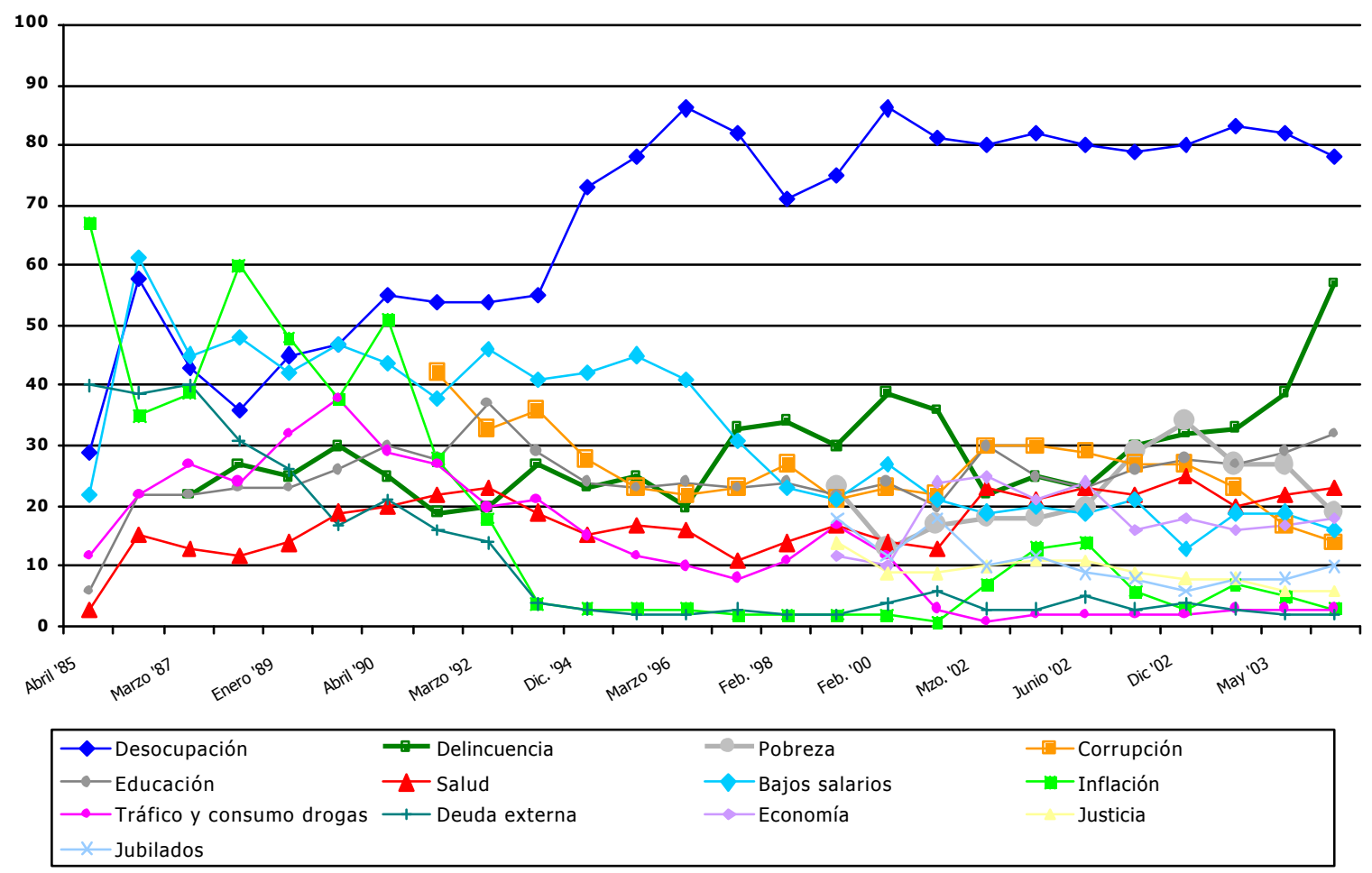

Figure 3 shows the public preference towards state enterprises and privatized enterprises.

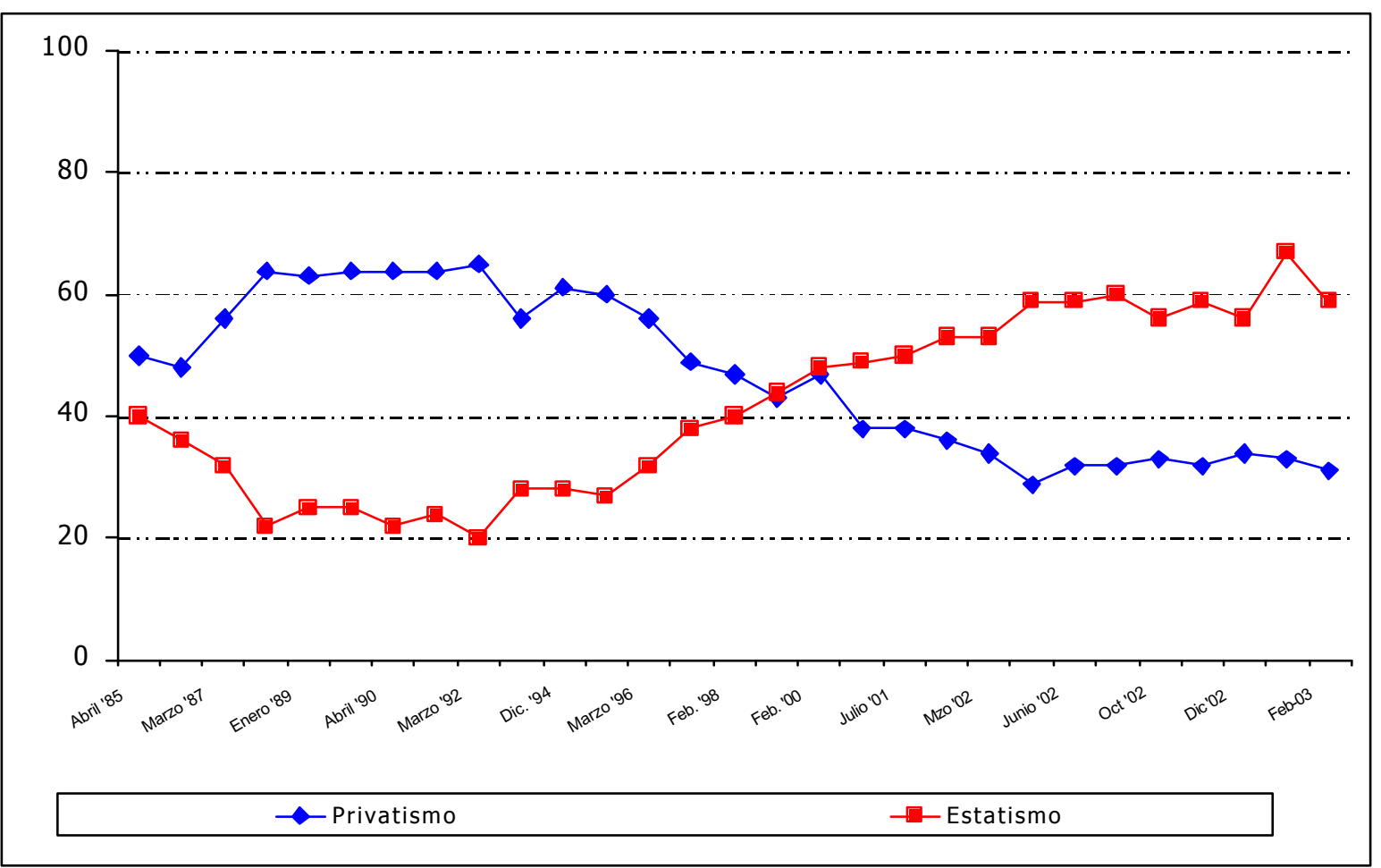


Note that during the second half of the eighties, when the public enterprises virtually collapsed, privatization was strongly popular. However, soon after the Menem administration actually privatized many state companies the support for this policy began to decline. In fact already in 1992 opinion polls showed a sharp drop in the support for privatization. Galiani et al show that privatizations led to a massive increase in investment, thus increasing access to services, specially by the poor, while keeping prices relatively constant. ${ }^{1}$ It is well known that the level of service provided by the privatized companies where by all standards far superior than the one provided by the previous state enterprises. Yet, as in the case of the economic plan, privatizations were a complex phenomena that offered many angles from where to judge them. In terms of service level per dollar, there was, indisputably, a sharply improvement (for example, before the telephone privatization, to get a new line it was not unusual to wait more than ten years, and apartments with telephone lines carried a big premium in the market versus identical apartments without a line. After privatization the waiting line for a telephone was reduced to less than a week). In addition the price of the services provided fell in many cases. However, in all cases, there were relatively massive outlays of formerly public sector employees. In addition, the process of privatization itself was, in many cases, suspected of corruption ${ }^{2}$. The lack of parameters to gauge whether the returns obtained by these companies was appropriate or not, or whether what had been paid to the state to acquire the companies or not, were other issues that the public had to make a judgment on. The negative view on the privatization process seems to suggest that, as soon as 1992, and more markedly since 1994 people apparently started to focus on those aspects of privatization that were not so positive.

At a more anecdotal level, when companies like Carrefour, WalMart and other local companies opened their hypermarkets in every major city in Argentina at the beginning of the nineties, prices were slashed and variety of products substantially increased. However, the process was subject to strong criticism. The public massively endorsed the use of the retail chain, substituting away from the more expensive and lower quality and diversity around-the-corner grocery store. As a consequence of this voluntary decision, grocers started loosing their jobs and business. Intriguingly, in casual conversation one could sense that peoples' opinions of the hypermarkets quickly turned against them (while as a customer people still used them for their purchases). This turn of the public opinion was not without consequences: it helped the grocers' lobby to influence legislators into passing laws prohibiting the free installation of more hypermarkets. As in the previous cases, among the many different angles from which one could look at the phenomenon of the hypermarkets people decided to focus selectively on some issues. While one could, quite naturally, argue that by far the most relevant factor on peoples' everyday life was the huge increase of quality, price and diversity of products now accessible for consumption, public opinion decided to focus mostly on the lost employment by the local grocers, or the fact that profits earned by the new retailer may not be invested in the local market.

\footnotetext{
${ }^{1}$ See Galiani, Sebastian, Paul Gertler, Ernesto Schargrodsky and Federico Sturzenegger (2003) The Benefits and Costs of Privatization in Argentina: A Microeconomic Analysis, Mimeo Universidad Torcuato Di Tella.

${ }^{2}$ See Gadano, Nicolas and Federico Sturzenegger (1998) "La privatización de reservas en el sector hidrocarburífero: el caso de Argentina" Revista de Análisis Económico, Vol. 13(1), June, pp. 75-115, for a description applied to the energy sector, and Maria Seoane (2003) El Saqueo de la Argentina, Buenos Aires, Ed. Sudamericana, for a critical evaluation of the process.
} 
The data just described beg some obvious questions. Why does a successful reform process have people turning quickly against it? How can it be that the same people that voted for the reelection of Menem in 1995, that decided to consume far more quantities than before of the products offered by the privatized companies (electricity, gas, telephone lines, highways, airplane tickets, etc.), and that decided to make all their home purchases at the newly installed hypermarkets answered to questions regarding their preferences for the economic plan, the privatized companies and the hypermarkets with increasing resentment?

If we were to apply straightforwardly the theory of revealed preferences we would probably conclude that the answer to these questions were just "cheap talk", but these answers are not without consequences, since it is well known that in a democracy politicians keep an eye on the preferences of the voters and decide policies at least partly based on them (for example as in the case of hypermarkets). In the Argentinean case in particular, the fact that the public opinion turned against (at least some aspects of) the reforms played an important role in the emergence of a contrarian discourse that begged for the need to spread the benefits of reforms more evenly. This pressure eventually generated doubts about the continuity of the reform process, undermining its sustainability.

How do people build their beliefs about the complex, many-sided politico-economical processes they are experiencing? Since these processes, as any real-world process, have many angles from where to look at them, the question requires understanding which of those angles are going to capture the attention of the public? And, will the public be "impartial" when judging these processes? These issues have so far been ignored in the reform literature, this paper is devoted to analyzing them.

A simplified version of where this story fits into our understanding of the reform process, and the traditional literature on reform, can described in the following graph.

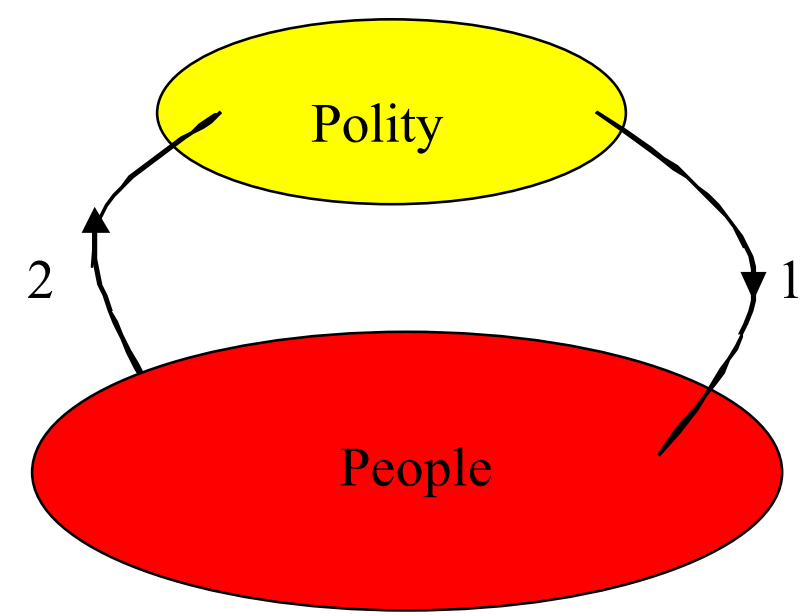

According to this scheme there are two types of interaction between the "polity" and the "people". We refer loosely to these two concepts, as they may represent different players, 
according to what interpretation of the reform process we may be discussing. The "polity" for example may refer to the institutional framework that determines government behavior in a pure incentive analysis of public policy, but it may also represent a constellation of interest groups in a purely non-cooperative game. The arrow indicated with number one refers to how the institutional framework may change policy outcomes or how the action of interest groups may affect economic outcomes. Most of the political economy literature, including the work of Olsen among many others, studies this link.

"People" on the other hand refers to the demands that the population imposes on the politicians. This entails understanding the preferences and beliefs of the population (which are taken as a given in political economy models) and understanding how they affect the political game. In the graph this is indicated by the arrow with a number two. These factors depend directly on cultural, historical and psychological factors. This area has been less studied by economists, but has received full attention from other social sciences. Fukuyama and Putnam, for example, are two scholars that strength the role of cultural and social factors (trust in the case of Fukuyama, and societal networks in the case of Putnam) in explaining societal outcomes. ${ }^{3}$ In this paper we focus on the arrow number two and we will argue that the preferences and beliefs of the population are endogenous to the structure of the society being analyzed.

A potentially useful analogy is the following. To study a market outcome one can study how market structure operates to generate a specific result in terms of equilibrium prices and quantities. This analysis, which presupposes given demand and supply curves, corresponds to arrow one in the graph above. However, it is necessary to understand where the demand curve comes from, a point on which economic analysis is, in general, silent. Yet it is studied intensively in disciplines such as "marketing" or "psychology". Implicit in a silent view on this issue is the hypothesis that the main characteristics and determinants of such demand curves are similar in every society. However we will argue that they are not. Moreover, we will argue that the main characteristics of the demand curve for policies, determined to a large extent by peoples' beliefs, constitute an endogenous variable in the political-economic game.

Arrow number two, corresponds to the equivalent of such analysis. The marketing analogy is correct, in the sense that it is useful to study, first, the underlying determinants of public opinion on reform (the psychology part) to be able to generate policy implications on how to shape that public opinion (if possible) to make it more supportive of welfare enhancing reforms. In other words, we need to understand the psychology of the customer in order to be able to "sell" the reform process. Only then can one tackle the task of putting together a useful political economy model that describes the equilibrium.

In this work we will try to analyze the factors that affect public opinion. We believe that the ultimate success of market oriented reforms in a democratic country should be measured by its ability to change public opinion to the point that the population finally

\footnotetext{
${ }^{3}$ See Fukuyama, Francis (1995) Trust. The social virtues and the creation of prosperity. London, Penguin, and Robert Putnam (1994), Making Democracy Work: Civic Traditions in Modern Italy, Princeton University Press.
} 
accepts the new rules of the game. But we will argue that when moving ahead with a reform process in the lines of the Washington consensus, we should expect to find a natural resistance from the population (particularly in underdeveloped nations) to support and acknowledge the positive aspects of the reform process. We call this phenomenon: resistance to reform.

We follow the same route of our psychology/marketing example above. We will first attempt to explain how public opinion locks into a specific view of the world, consistent with the state of affairs prior to reform. We will then assume that a reform takes place (we do not discuss here the reasons why such reform happens) and discuss how public opinion naturally tends to stress the negative views of the reform process. We end up by discussing how this resistance to reform places additional challenges on the policy maker previously ignored by the literature.

The rest of the paper is then organized as follows: in section 2 we will describe some very well known findings in psychological and behavioral-economic literature. In section 3 we will use this psychology to motivate our main hypotheses about how societies produce an endogenous "vision of the world". It is important to stress that our hypotheses about the visions likely to prevail in different societies are based in completely universal features of human cognition as described by psychologists and that are playing and increasingly important role in the sub-field of evolutionary psychology ${ }^{12}$ as well as in behavioraleconomics. Their validity, then, should be tested against the observed visions in all societies and not only on those who underwent reform processes. As a particular case we will study in detail the visions likely to prevail in underdeveloped nations, which are our main interest in this study. Finally, in section 4 we will use the results of the previous section to explain why, as in the evidence presented in this introduction, public opinion is likely to turn quickly against the reform process. We then discuss what lessons emerge from this.

\section{Universal Cognitive Biases}

To understand the formation of "visions of the world" from an economic perspective it is useful to bring into the picture some tools about human cognition used by many new developments in the field of behavioral economics that come from psychological research. Surprisingly, to our knowledge there have not been many applications of this growing field to political-economy issues even though most of the cognitive features we are going to use play and important role in human information processing mainly in complex social environments in which agents have to apply some criteria to make choices. And it does not get any more complex than the political process that citizens have to interpret to be able to make decisions, more so if this process is changing as a result of reforms.

Thus, in order to understand how societies build a belief structure, we review some developments about two important universal aspects of human cognition: confirmatory bias and self-serving bias (in particular two subsets of the research in this area: attribution theory and self-serving assessments of fairness). 


\section{1. Universal Cognitive Biases}

\subsubsection{Confirmatory bias}

A person suffers from confirmatory bias if he tends to misinterpret ambiguous evidence as confirming his current hypothesis about the world. Psychological research provides strong evidence that confirmatory bias is a standard feature of our cognitive make up. Lord, Ross, and Lepper ${ }^{4}$ described some underlying mechanisms responsible for such propensities:

...there is considerable evidence that people tend to interpret subsequent evidence so as to maintain their initial beliefs. The biased assimilation process underlying this effect may include the propensity to remember the strengths of confirming evidence but the weaknesses of disconfirming evidence, to judge confirming evidence as relevant and reliable but disconfirming evidence as irrelevant and unreliable, and to accept confirming evidence at face value while scrutinizing disconfirming evidence hypercritically. With confirming evidence, we suspect that both lay and professional scientists rapidly reduce the complexity of the information and remember only a few well-chosen supportive impressions. With disconfirming evidence, they continue to reflect upon any information that suggest less damaging "alternative interpretations". In fact, they may even come to regard the ambiguities and conceptual flaws in the data opposing their hypothesis as somehow suggestive of the fundamental correctness of those hypotheses. Thus, completely inconsistent or even random datawhen "processed" in a suitably biased fashion - can maintain or even reinforce one's preconceptions.

Interestingly, the most striking evidence for confirmatory bias comes from experiments in which the subject matter is complex, and in many cases with political connotations, which strongly suggest that this systematic bias should play and important role in shaping peoples' beliefs about a political process.

In the above mentioned paper, Lord, Ross, and Lepper asked 151 undergraduates to answer a questionnaire that included three questions on capital punishment. 48 of them were selected for a second run. Half of them had answered three questions revealing that they were 'proponents' of capital punishment believing in its deterrent effect, while the other half revealed they were 'opponents' of it and doubted of its deterrence effect. These subjects where asked to rate, on a 16 point scale ranging from -8 to +8 , whether randomly selected studies on the deterrence effect of capital punishment moved their attitude towards death penalty, and how they had changed their beliefs regarding its deterrence efficacy. Surprisingly the results indicated that those that had a prior in favor of the death penalty read the evidence as supporting their prior. Similarly, those against read the same evidence as supportive of a view unfavorable to the death penalty. With a confidence $p<.01$, the

\footnotetext{
4 "Biased Assimilation and Attitude Polarization: The Effects of Prior Theories on Subsequently Considered Evidence", Journal of Personality and Social Psychology, XXXVII (1979), 2098-2109.
} 
authors found that the experiment provided strong support for the polarization hypothesis: providing the same ambiguous information to people who differ in their initial beliefs (in this case on capital punishment) can move their beliefs farther apart.

Plous ${ }^{5}$ find similar results in the context of judgments about the safety of nuclear technology. Darley and Gross ${ }^{6}$ found a similar polarization induced by confirmatory bias in the following experiment: seventy undergraduates where asked to assess the skill of a young girl on various academic areas. Before completing the assessment, they where given information about the girl's background and viewed a video tape of the girl playing in a playground. For one group of students that we call W, the information they received described the girl's parents as college graduates with a white collar job; these student viewed the videotape of the girl playing in a well-to-do, middle class neighborhood. The other group (B) received information describing the girl's parents as high school graduates who held blue collar jobs; their videotape showed at the same girl playing in an impoverished inner-city neighborhood. Each group $\mathrm{W}$ and $\mathrm{B}$ where then divided into two halves: W1, W2, B1 and B2. The subgroups W1 and B1 where asked to evaluate the girl's reading level, measured in terms of equivalent grade level. W1 rated her reading level at an average of 3.90 (i.e., 9/10 through third grade) while B1 rated her reading level at an average of 4.29. W2 and B2 where shown a second video of the girl answering a series of questions some of which she answered right and others wrong. After they viewed the second videotape they were asked to evaluate the girl's reading level. B2 rated her reading level at an average of 3.71, significantly below the 3.90 estimate of B1. On the other hand, W2 rated her reading level at an average of 4.67, significantly above the 4.29 estimate of $\mathrm{W} 1$ (who did not view the second video). Even though $\mathrm{B} 2$ and $\mathrm{W} 2$ viewed exactly the same second video, the additional information further polarized their assessments of the girl's skill level. The authors interpret the results as evidence of confirmatory bias, clearly the students where influenced in their judgment by the information they received about the girl, but they where influenced even more by their initial hypothesis about the girl and their subsequent interpretation of additional data.

When the information is about the physical world, which allows for reality checks by multiple observers and where misconceptions are likely to harm the perceiver, confirmatory bias (and other bias to be discussed later) tend to be almost non-existent. But when people must interpret ambiguous evidence that requires a criterion of interpretation, researchers observe systematic biases in such interpretations. For example in their interpretations of causality between politico-economic events, we hypothesize that people will tend to interpret the same data in a way that confirms their ideology or any other prior that they may have. Confirmatory bias also occurs when people selectively collect or scrutinize evidence $^{1}$. Rabin and Schrag also mention another mechanism that we believe plays an important role in peoples' formation of beliefs about the political process they are experiencing. It is what they call "positive test strategy": people tend to ask questions that are likely to be true if their hypothesis are true, without considering that they are also likely

\footnotetext{
5 "Biases in the Assimilation of Technological Breakdowns: Do Accidents make us safer?" Journal of Applied Social Psychology, XXI (1991), 1058-1082.

6 "A Hipothesis -Confirming Bias in Labeling Effects", Journal of Personality and Social Psychology, XLIV, (1983), 20-33.
} 
to be true if their hypothesis are wrong, and interpret the fact that they are true as confirming their "theory" about reality.

We want to stress the fact that the experiments we have just described, as well as many others, show that additional information polarizes the position of people having different initial beliefs. This goes completely against the traditional Bayesian (intuitive) assumption that additional information should lead the two groups to converge in their opinions. But not surprising when realizing that it is absolutely familiar to followers of political news and debates, in which people with different ideologies interpret exactly the same data in completely different (and sometimes opposing) ways.

Many other experiments show that people truthfully believe in their position and interpretation of the data, which makes the eventual reaching of an agreement between them much harder as we will see shortly.

\subsubsection{Self-Serving Bias}

The next systematic bias we will explore is known as "Self-Serving Bias", i.e., the tendency of people to truly believe the hypothesis that best serves their selfish interests.

Although psychologists are not in complete agreement about the origin of self-serving bias, their existence is rarely questioned. For example, numerous surveys find well over $50 \%$ of the people rating themselves in the top $50 \%$ of drivers ${ }^{7}$, ethics ${ }^{8}$, managerial prowess ${ }^{9}$, productivity ${ }^{10}$, health ${ }^{11}$, and a variety of desirable skills. When married couples estimate their contribution to family life, their fractions usually add up to more that $100 \%{ }^{12}$. The self-serving bias affects not only individuals' evaluations of themselves, but also of groups they are affiliated with ${ }^{13}$.

\subsubsection{Attribution Theory}

There is a whole area of psychological research, known as "attribution theory" which among other things concludes unambiguously that people attribute their success to ability

\footnotetext{
7 “Are We all Less Risky and More Skillful Than Our Fellow Drivers?”, by Svenson, Ola, Acta Psychologica, February 1981, 94, 143-148.

8 “An Honest Profit", by Baumhart. New York: Prentice-Hall, 1968.

9 "Managerial Myopia: Self-Serving Biases in Organizational Planning”, by Larwood, L. and Whittaker, W., Journal of Applied Psychology, April 1977, 62, 194-198.

10 “Not Can, But Will College Teaching be Improved?", by Cross, K. P., New Directions for Higher Education, Spring, 1977, 17, 1-15.

11 "Unrealistic Optimism about Future Life Events", by Weinstein, N. D., Journal of Personality and Social Psychology, November 1980, 39, 806-820.

12 "Egocentric Biases in Availability and Attribution", by Ross, M., and Sicoly, F., Journal of Personality and Social Psychology, March 1979, 37, 322-336.

13 "They Saw a Game: A Case Study", by Hastorf, A., and Cantril, H., Journal of Abnormal and Social Psychology, 1954, 49:1, 129-134.
} 
and skill but their failure to bad luck or bad intensions of others ${ }^{14}$. The famous MIT Psychologist Steven Pinker describes this tendency to self-deception ${ }^{15}$ :

...The conventional view (that natural selection favors nervous systems which produce ever more accurate images of the world) may be largely correct when it comes to the physical world, which allows for reality checks by multiple observers and where misconceptions are likely to harm the perceiver. But as Trivers notes, it may not be correct when it comes to the self, which one can access in a way that others cannot and where misconceptions may be helpful. Sometimes parents may want to convince a child that what they are doing is for the child's own good, children may want to convince parents that they are needy rather than greedy, lovers may want to convince each other that they will always be true, and unrelated folks may want to convince each other that they are worthy cooperators. These opinions are often embellishments, if not tall tales, and to slip them beneath a partner's radar a speaker could believe in them so as not to stammer, sweat, or trip himself up in contradictions. Ice-veined liars might, of course, get away with telling bald fibs to strangers, but they would also have trouble keeping friends, who could never take their promises seriously. The price of looking credible is being unable to lie with a straight face, and that means a part of the mind must be designed to believe its own propaganda- while another part registers just enough truth to keep the self-concept in touch with reality...

...In social psychology experiments, people consistently overrate their own skill, honesty, generosity, and autonomy. They overestimate their contribution to a joint effort, chalk up their successes to skill and their failures to luck, and always feel that the other side has gotten the better deal in a compromise. People keep up these self-serving illusions even when they are wired to what they think is an accurate lie detector. This show that they are not lying to the experimenter buy lying to themselves...

\subsubsection{Self-Serving biases in judgments of fairness}

A subset of research in Self-Serving Bias deals with biases in judgments of fairness, in which people tend to see as fair or right what helps their self-interest ${ }^{16}$. Whenever individuals face tradeoffs between what is best for themselves and what is morally correct, their perceptions of moral correctness are likely to be biased in the direction of what is best for themselves. In making the tradeoff, then, self-interest enters twice-directly, when it is

\footnotetext{
${ }^{14}$ See, for example, "Attribution of Success and Failure Revisited, Or: The Motivational Bias is Alive and Well in Attribution Theory", by Zuckerman, M, Journal of Personality, June 1979, 47, 245-287.

15 "The Blank Slate: The Modern Denial of Human Nature”, by Steven Pinker, Viking, 2002, Chapter 14.

${ }^{16}$ See for example "Fairness and Preference", by Messick, D., and Sentis, K., Journal of Experimental Social Psychology, 1979, 15:4, 418-434.
} 
traded off against moral correctness, and indirectly, via its impact on perceptions of moral correctness $^{17}$.

Experiments carried out by Linda Babcock, George Loewenstein and others, are particularly relevant for us for their closeness to our application to a political process. The underlying theme of these studies is the extent to which failures, or impasses, in bargaining can be attributed to self-serving bias. The standard, game-theoretic explanation of delays in settlements is based on incomplete information and costly signaling about reservation values $^{18}$. Babcock and Loewenstein, on the other hand, argue that self-serving bias in judgments - to confuse what is fair with what benefits oneself - is an important determinant of bargaining impasse. They look at examples in which different criteria can be selected in the negotiation to decide what is fair or convenient.

The authors developed a tort case on a legal case that occurred in Texas ${ }^{19}$, in which an injured motorcyclist sued a car driver for a collision, requesting him $\$ 100,000$. Subjects were randomly assigned the role of plaintiff or defendant to negotiate the settlement. Boths subjects receive a page with clear instructions about the experiment and the same 27 pages of materials of the original case in Texas. In principle both plaintiffs and defendants have exactly the same information as the judge in Texas.

Before negotiating subjects had to write down their guesses of what the real judge awarded, with monetary gains for them if their guesses where within $\$ 5,000$ of the real award. They also had to write down what they considered a fair amount for the plaintiff for reaching an agreement out of court. They where then allowed to negotiate for 30 minutes to reach an agreement with clear rules for gains and looses and penalties if they did not reach the agreement.

The experiment was designed to test for self-serving bias in a contextually rich and at the same time controlled setting. Note that in this experiment it is explicit that there are no differences in information since both parties know that the other party has exactly the same information.

In a first series of experiments ${ }^{20}$ the subjects were 38 public policy students at Carnegie Mellon University, 120 law students from the University of Texas and 30 business students from the University of Pennsylvania. The authors found strong evidence that the negotiators formed self-serving assessments of the judge's award (plaintiffs' predictions averaged \$14,527 higher than defendants'), and that the discrepancy between the plaintiffs'

\footnotetext{
17 "Behavioral Decision Theory and Business Ethics: Skewed Tradeoffs Between Self and Other", by Loewenstein, G., in Messick, D. and Tenbrunsel, A., eds., Codes of Conduct: Behavioral Research into Business Ethics. New York: Russell Sage Foundation, 1996, 214-227.

18 "Strategic Bargaining Models and Interpretation of Strike Data", by Kennan, John, and Robert Wilson, Journal of Applied Econometrics, December 1989, 4, 87-130, and "Strategic Delay in Bargaining with TwoSided Uncertainty”, by Peter Crampton, Review of Economic Studies, January 1992, 59, 205-225.

19 "Explaining Bargaining Impasse: The Role of Self-Serving Biases", by Linda Babcok and George Loewenstein, Journal of Economic Perspectives, V. 11-1, Winter 1997, 109-126.

20 "Self-Serving Assessments of Fairness and Pretrial Bargaining”, by Loewenstein, G., Issacharoff, S., Camerer, C., and Babcock, L., Journal of Legal Studies, January 1993, 22, 135-159.
} 
and defendants' assessments where correlated with the parties' ability to reach voluntary settlements. Also, plaintiffs' fair settlement values averaged \$17,709 higher than defendants'. Both differences are statistically different from zero $(\mathrm{p}<.0001)$.

In a different paper ${ }^{21}$ they introduced a manipulation in the experiment to make sure that self-serving bias caused impasse. They change the order of events in the experiment. In the control condition, the participants learned whether their role would be defendant or plaintiff before they read the case materials and offered their anonymous assessments of the judge and a fair settlement; in the experimental condition they learned their role after reading the materials and offering their anonymous assessments of the judge and a fair settlement.

Consistent with a causal relationship running from the self-serving bias to impasse, when the subjects did not learn their roles until after they read the case and made their assessment of the judge and fairness (in which now they did not have a statistically significant difference), only $6 \%$ of the negotiations where resolved by the judge; however, when the subjects knew their roles initially, $28 \%$ of the negotiations had to be resolved by the judge (a statistically significant difference).

This result is also consistent with previous research ${ }^{22}$ in self-serving bias that suggests that the bias results from selective information processing. This was more directly confirmed ${ }^{18}$ by giving subjects a questionnaire at the end of the bargaining session in which they where asked to rate the importance of a series of eight arguments favoring the plaintiff and eight favoring the defendant. Consistent with the "selective information processing" hypothesis plaintiffs tended to weight arguments favoring the plaintiff as much more compelling than those favoring the defendant and vice versa. The authors consider that this provides evidence that the self-serving bias results form role-dependant evaluation of information.

In a field study ${ }^{23}$ the authors examine the bias and its impact on bargaining in a real-world setting - public school teacher contract negotiations in Pennsylvania. Among other things, this study shows that self-serving bias also affects experienced negotiators.

In public sector contract negotiation, it is commonplace to make references to agreements in "comparable" communities. The authors tested for self-serving bias in the selection of comparables. They surveyed union and school board presidents from all school districts in Pennsylvania to obtain a list of districts that they viewed as comparable for purposes on salary negotiations. The authors then analyzed the responses comparing it to information about strikes, teacher's salaries, community salary levels, and other information. The

\footnotetext{
21 "Biased Judgment of Fairness in Bargaining”, by Babcock, L., Loewenstein, G., Issacharoff, S., Camerer, C., American Economic Review, 1995, 85:5, 1337-1343.

22 "Ambiguity and Self-Evaluation: The Role of Idiosyncratic Trait Definitions in Self-Serving Assessments of Ability”, by Dunning, D., Meyerowitz, J. A., and Holzberg, A. D., Journal of Personality and Social Psychology, December 1989, 57, 1082-90. See also "A Hypothesis -Confirming Bias in Labeling Effects", by Darley, J. M., and Gross, P. H., Journal of Personality and Social Psychology, January 1983, 44, 20-33.

23 "Choosing the Wrong Pond: Social Comparisons that Reflect Self-Serving Bias", by Babcock, L., Wang, X., and Loewenstein, G., Quarterly Journal of Economics, February 1996, 111, 1-19.
} 
authors could then examine the relation between strike activity and the subjective perceptions of the respondents.

The authors found that among the districts in which both the union and school board returned the survey, the number of district that they found as comparable where about the same, but the composition reflected a statistically significant self-serving bias (with the union choosing comparables with average salaries higher than the comparables chosen by the school district).

To test for the effect of self-serving bias on strikes the authors regressed the percentage of previous contract negotiations that ended in strike against the difference in the average salaries of the two parties list of comparables, including, of course, controlling variables. Their regression found a significant effect of the difference in the list of comparables on strike activity (each $\$ 1,000$ difference in the set of comparables of the union and the school board implied a $49 \%$ higher likelihood of strike). They also found that the difference in the list of comparables was correlated with the variance in the salaries in the neighboring districts. A larger variation provides more opportunity for each side to choose self-serving comparison groups.

The fact that each side chooses a set of comparables that favors her position is not in itself evidence of self-serving bias, since the bias could be simply a negotiation strategy. In fact, the authors believe that part of the story involves strategic selection of comparables.

However, if a rational strategy is all there is, they should find ways to reach an agreement with the other party since non-agreement is costly to both sides. The fact that the greater the difference between the comparable set of the two sides, the greater the probability of non-agreement, is then interpreted as evidence that such difference is not strategic. It is the result of an unconscious selection bias together with an intrinsic desire to reach agreements seen as fair by both sides. Their own privately held (sincere) view of comparables is likely to affect their own "reservation salary". When the comparables they privately view as relevant are too far apart, impasses will be likely to occur.

In addition to testing for self-serving bias in the selection of comparables, the authors also tested for bias in the assessment of relevance of comparisons in the negotiation. In teacher contract negotiation the two sides sometimes compare teacher's salary, not only with teacher salaries in other districts, but also with salaries of community members in the same district. As it is to be expected, board presidents in poor communities believe that community salaries should be given substantial weight in the determination of teacher salaries while board presidents in wealthy communities do not, and vice versa for union presidents. Also, in districts surrounded by neighboring districts paying their teachers high salaries, boards view these neighbors as being less important for comparison purposes than do boards in districts that are surrounded by districts that pay teachers low salaries.

\section{Political beliefs as an endogenous variable}


With these elements we are now able to address how public opinion locks itself in a particular view of the world depending on some characteristics of that society. We do this by following a two step process: first we discuss the visions likely to be embraced by individuals as a function of their socio-economic situation as well as their life experience. Then we derive the visions that are likely to be popular in different societies by simply looking at the characteristics of the typical individual in a society characterized by a given level of wealth, distribution of wealth, etc.

It is worth emphasizing here that our hypotheses about the likely political beliefs embraced by individuals are supposed to be valid for what we called the "people" in the Introduction.

Visions likely to be embraced by individuals as a function of their socio-economic situation as well as their life experience

Consistent with attribution theory, people with low income or people who descended in the social ladder will tend to associate their personal economic situation to the external environment. Ideas such as exploitation from the rich, corruption by the powerful, lack of opportunities, find fertile ground among this group as they help to justify, in a self-serving manner, their situation. In general, the argument relies on the fact that their situation is determined by society and is not due to their own effort. They will believe in such "theory" about how their society works and when interpreting new politico-economical data, in line with the confirmatory bias hypothesis they will tend to view such data as confirming that hypothesis about the world. Also, according to self-serving biases in their judgments of fairness, they will consider the wealth of the rich or of those who progress as underserved and perhaps even the product of immoral actions that should be punished. They will believe then, that it is only fair to adopt a strong policy of redistribution of wealth from the rich towards them and will tend to vote for it.

On the other hand, consistent with attribution theory, people with high income or people who progress in life will tend to attribute their personal economic situation to their own merits, free will, and will believe in the fact that even if society does not make things easy, it is possible to shape your own destiny with effort and will. They will believe in such "theory" about how their society works and when interpreting new politico-economical data, according to confirmatory bias they will tend to view such data as confirming their current hypothesis about the world. Also, according to self-serving biases in their judgments of fairness, they will consider as fair a policy that respects (and does not tax heavily) the property of those who earned their income with effort. Of course, they will tend to vote for those policies.

\section{Visions that are likely to be popular in different societies}

The visions likely to be popular in different societies are simply the visions of the individuals characterized by a level of wealth and progress in life representative of the majority in the given country. It is almost a tautology that the level of wealth of the average individual in rich societies is higher than the level of wealth in poor, underdeveloped societies. It is also usually true that the distribution of wealth in poor nations is worse that in rich nations. In this context, this simple analysis provides an 
explanation to the fact that, in general, poor nations will tend to have a vision of the world in which there is a tendency to ask for more government intervention in order to reverse the unfairness of the forces that determine societal outcomes.

It is hardly necessary to add that our theory about the endogeneity of the visions of the world likely to prevail in a given society do not preclude the existence of other factors influencing them. As any complex social phenomena, the formation of visions of the world surely recognizes many causes. However, we will show some evidence that suggests that our theory does possess explanatory power.

As we mentioned in the Introduction, our hypotheses about the visions likely to prevail in different societies are based in completely universal features of human cognition. Their validity, then, should be tested against the observed visions in all societies and not only on those who underwent reform processes.

We will show evidence that supports our hypotheses in a two-step process: first we present evidence on the visions likely to be embraced by individuals as a function of their socioeconomic situation as well as their life experience without taking into account the societies they belong to. We then present evidence about visions that are popular in different societies. The evidence comes from a recent paper by Rafael Di Tella and Robert MacCulloch $^{24}$.

The source of data is the World Values Survey Series. Di Tella and MacCulloch show empirically that individuals who perceive corruption to be widespread are more likely to support distributionist policies. The result is robust and survives to the inclusion of control variables such as level of income and education, etc. Level of income enters these regressions with the right sign from the perspective of our theory: lower income people tend to lean ideologically towards redistributionist policies. As mentioned before, according to our theory, people with low income will find it self-serving to attribute to corruption or immoral actions the wealth of those who do progress.

They also show that people who defend distributionist policies and tend more often to perceive corruption in society are more likely to reject the idea that poverty is due to lack of effort and favor the idea that the poor are unfairly treated by society and that government is doing too little to alleviate poverty. Again this neatly fits the pattern suggested by our hypotheses.

In the survey people are asked to "Imagine two secretaries, of the same age, doing practically the same job. One finds out that the other earns considerable more than she does. The better-paid secretary, however, is quicker, more efficient and more reliable at her job. In your opinion, is it fair or not fair that one secretary is paid more than the other". In accordance to the self-serving biases in the judgment of fairness hypothesis, individuals who favor distributionist policies and perceive corruption to be widespread are more likely to say that it is not fair to pay more to the efficient secretary.

24 “Why doesn't Capitalism flow to Poor Countries?”, by R. Di Tella and R. MacCulloch. 
We see then, with data coming from 51 nations, that at the individual level we find empirical support for our hypothesis. All the evidence reviewed here can be seen quantitatively in the paper ${ }^{22}$.

Is it also valid to assume that these visions aggregate linearly when moving to the "society level"? ${ }^{25}$ In the same paper the authors show evidence in this regard (for data on policy preferences or ideological leanings of a country's decision makers they rely on Beck et al, 2001 ${ }^{26}$ ). In their Table A1 they show the frequencies of governments (as defined by the political color of the Chief Executive and classified as left, center and right), both in OECD countries as in non OECD countries. Consistent with the hypothesis that individual beliefs aggregate to the societal level, underdeveloped countries tend to vote more often for strongly redistributive and interventionist governments (Left). The table is as follows:

Table A1: Frequency of Political Color of Government, OECD vs Non OECD

\begin{tabular}{|l|c|c|}
\hline & OECD & Non-OECD \\
\hline Left & $198(39.4 \%)$ & $1,083(60.7 \%)$ \\
\hline Center & $49(10.4 \%)$ & $115(6.2 \%)$ \\
\hline Right & $241(50.2 \%)$ & $625(33.1 \%)$ \\
\hline Total & $488(100 \%)$ & $1,823(100 \%)$ \\
\hline \multicolumn{2}{|c|}{} \\
\hline
\end{tabular}

Note: Frequencies of government (definition used is Chief Executive). Percentage of group in parentheses. Based on 177 countries over the period 1975 to 1997.

The result is robust, as it remains basically unchanged if a different criteria is used to define rich and poor countries and the color of government. In Table A2, which we reproduce here, the authors show that dividing the 177 countries symmetrically by thirds on the basis of income (real purchasing power parity) and defining government in a way that follows more closely the electoral appeal based on the color of the largest government party, the tendencies remain unchanged.

Table A2: Frequency of Political Color of Government by Income Group

\begin{tabular}{|l|c|c|c|}
\hline & Top Income $\left(1^{\text {st }}\right)$ & Middle Income $\left(2^{\text {nd }}\right)$ & Bottom Income $\left(3^{\text {rd }}\right)$ \\
\hline Left & $244(37.7 \%$ & $290(45.0 \%)$ & $436(67.6 \%)$ \\
\hline Center & $78(12.1 \%)$ & $59(9.2 \%)$ & $62(9.6 \%)$ \\
\hline Right & $325(50.2 \%)$ & $295(45.8 \%)$ & $147(22.8 \%)$ \\
\hline Total & $647(100 \%)$ & $644(100 \%)$ & $645(100 \%)$ \\
\hline
\end{tabular}

Note: Frequencies of government (definition used is "largest government party") for 177 countries over the period 1975 to 1997 . Percentiles within income group in parentheses.

\footnotetext{
${ }^{25}$ In fact, if the visions held by the majority were to imply, as it is natural to assume, the implementation of policies congruent with such vision, then nonlinear effects could in fact emerge...

${ }^{26}$ Beck, Thorsten, George Clarke, Alberto Groff, Philip Keefer, and Patrick Walsh, (2001) "New tools in comparative political economy: The Database of Political Institutions." World Bank Economic Review.15: 1, 165-76.
} 
The authors also show that the pattern has remained basically unchanged during the subperiods (1975-80) and (1992-7).

The authors explore other metrics that can be used to define the color of government. For all definitions of government they find that a simple t-test suggests that pro-market parties are more common in richer countries, and that there do not seem to be significant trends over time. It seems then that it is a robust empirical result that poor countries vote more than rich countries for strongly redistributive policies as our theory predicts.

In their Table A5 the authors show that, on the one hand, the top third richest countries have a better income distribution than the low third poorest countries (income distribution is measured by the Gini by Deininger and Squire (1996)). But within the group of poor countries those with low inequality had relatively more left wing governments than those with high inequality.

Table A5: Frequency of Political Color, by Income and Inequality Levels

\begin{tabular}{|l|l|c|c|}
\hline & & Top Income $\left(1^{\text {st }}\right)$ & Bottom Income $\left(3^{\text {rd }}\right)$ \\
\hline & Left & $111(44 \%)$ & $43(96 \%)$ \\
\hline Low Inequality & Center & $24(10 \%)$ & $0(0 \%)$ \\
\hline & Right & $116(46 \%)$ & $2(4 \%)$ \\
\hline & Total & $251(100 \%)$ & $45(100 \%)$ \\
\hline & & & \\
\hline & & Top Income $\left(1^{\text {st }}\right)$ & Bottom Income $\left(3^{\text {rd }}\right)$ \\
\hline & Left & $19(27 \%)$ & $68(58 \%)$ \\
\hline High Inequality & Center & $24(34 \%)$ & $8(7 \%)$ \\
\hline & Right & $27(39 \%)$ & $42(35 \%)$ \\
\hline & Total & $70(100 \%)$ & $118(100 \%)$ \\
\hline
\end{tabular}

This is again consistent with our theory since part of the structural characteristics of a society that determine its belief structure is the distribution of wealth: in rich countries there is a relatively lower proportion of people with low income.

We want to emphasize that, according to our mechanism of political beliefs formation, cognitive biases have a critical influence on public opinion. It is not necessarily the case that rich countries' people are wiser than poor countries' people and therefore tend more often to support the right policies. It is the cognitive biases that don't allow to realize that better policies are available.

As an extra ingredient, external to our mechanism, the fact that poor countries tend to adopt strongly redistributive policies implies that they build societies with lesser incentives to create value and an increased incentive for corruption. This makes these countries to selfperpetuate as underdeveloped in a vicious circle. On the contrary, in rich nations people tend to live better and they tend to have more self-serving reasons to attribute their fate to 
their effort. By the mechanism explained above they will tend to vote more often for policies that protect the results of these efforts. This makes these countries to selfperpetuate in a virtuous circle. But again, not because their people "know it better" but because it just happen to be the case that these policies fit with their self-serving biases.

The just mentioned self-sustained beliefs have been formalized in Alesina and Angeletos ${ }^{27}$ who show in the context of Europe versus US that if a society believes that luck or corruption (rather than effort) determine wealth, it will choose high (rather than low) taxes, thus distorting allocations and making these beliefs self-sustained. This paper can be seen as formalizing this extra ingredient that we mentioned before but should not be confused with our claims about the cognitive biases that induces the beliefs in the first place.

Similarly, while one would believe it should be natural to expect for poor countries to try to copy rich countries, people from underdeveloped countries, in accordance with the selfserving bias hypothesis might tend to explain the underdevelopment of their country as a result of exploitation from the rich and powerful countries and not so much as a result of bad policies that the country adopted. Moreover, some people in underdeveloped nations may even believe that the very rich of their own country are in some kind of connivance with the rich nations to exploit them, by "selling" the country to the rich nations and ensuring its dependence. The point is that if they believe in such "theory" about how the world works, when interpreting new global politico-economical data, according to confirmatory bias they will tend to view such data as confirming their current hypothesis about the world. Also, according to self-serving biases in their judgments of fairness, they will consider the wealth of the rich nations as underserved and as fair, for example, not to pay the external debt.

If this were the case, according to psychological research they would truly believe in their theory, and they would correspondingly not believe that the rich countries are rich because they organize themselves better. Therefore they will have no intention of voting for politicians who propose systems similar as those prevailing in rich nations. The fact that poor countries do not vote for capitalist policies, is then further evidence that the mechanism at work is cognitive bias. People truly believe in their theories, otherwise they would not accept the costs associated with their position (this argument is analogous to the one done to justify that self-serving bias and not only strategic positioning was at work between unions and school boards). This is one instance in which the self-serving bias is, in the general equilibrium game, in fact self-defeating. As Pinker said ${ }^{5}$ :

...Self-deception is among the deepest roots of human strife and folly. It implies that the faculties that ought to allow us to settle our differences seeking the truth and discussing it rationally - are miscalibrated so that all parties assess themselves to be wiser, abler, and nobler than they really are. Each party to a dispute can sincerely believe that the logic and evidence are on his side and that his opponent is deluded or

\footnotetext{
27 "Fairness and Redistribution: U.S. Versus Europe", by Alesina, A., and Angeletos, G-M., NBER Working Paper No. 9502, February 2003.
} 
dishonest or both. Self-deception is one of the reasons that the moral sense can, paradoxically, often do more harm than good...

On the contrary, people from developed countries, according to self-serving bias (regarding in this case the group they belong to), might tend to explain the wealth of their country as a result of the effort of their citizens and the civilized way in which their country is organized. They may also tend to explain underdevelopment as the result of bad policies in the underdeveloped nations and that what these countries need to do is just copy them, disregarding the extra difficulties that underdeveloped nations may face to implement the same policies in a completely different social scenario.

\section{Resistance to Reform}

Let us remember the questions posed in the Introduction: Why does a successful reform process have people turning quickly against it? How can it be that the same people that voted for the reelection of Menem in 1995, that decided to consume far more quantities than before of the products offered by the privatized companies (electricity, gas, telephone lines, highways, airplane tickets, etc.), and that decided to make their home purchases at the newly installed hypermarkets, answered to questions regarding their preferences for the economic plan, the privatized companies and the hypermarkets with an increasingly negative view about their presumed contribution to the economy?

We have suggested a way of thinking about how people build their political beliefs. This theory tells us that in order to predict the beliefs that are going to be held by a majority in a given society we have to look at some basic socio-economic structural characteristics of such society since political beliefs are endogenous.

Argentina is a country that used to be among the ten richest countries of the world at the beginning of the twentieth century. However, it has slowly stagnated since. Starting in the mid 70s meager growth gave way to total stagnation, and with total stagnation politics and economic policy became far more unstable. Losing a war against the UK at the beginning of the eighties and reaching the end of the same decade with hyperinflation and social unrest, depict a society where policies were not conducive to economic growth. While the distribution of wealth was not as bad as in other Latin American countries, during the 80s it suffered a continuous deterioration.

These simple facts are enough to guess that in Argentina the majority of its citizens suffered a process of impoverishment than economic progress, and it is probably correct that their economic fate during all those years was more determined by the society they lived in (and the random shocks it generated) than by their own efforts. Thus, although the society was desperate for a radical change in the way it organized itself, our theory suggests that the Argentina that underwent the reforms at the beginning of the nineties did so with deeply held underlying political beliefs that society and its macroeconomic environment, and not individual effort, determined economic progress. Needless to say, these beliefs were very much at odds with the capitalist principles that shaped the reform. 
Our theory also suggests then that, unless the reforms could quickly and dramatically change the socio-economic structural characteristics of the society, which we claim is the key determinant of political beliefs, such deeply held beliefs would surface sooner or later, creating a negative attitude towards reform. This is the basic mechanism that we will use to explain the empirical evidence presented in the introduction.

But before we do this we have to address the question of why, with such political beliefs, a country like Argentina would undergo a pro-market reform to start with. In this sense, it is important to point out that when Menem won the election, the party of the then president Raul Alfonsín had virtually no chance of winning given the current state of the economy, when inflation was rampant and poverty had skyrocketed. Whoever was the peronist candidate was bound to win. And the Peronist candidate was Carlos Saul Menem, who had nothing in his background suggesting he would produce a pro-market capitalist reform. Just in case anybody suspected something, he run a campaign at the best Latin American populist style. His slogan was the empty statement: "Follow me, I am not going to disappoint you"28, without giving any hint about a capitalist program. ${ }^{29}$ The fact was that the Argentinean economic situation was so desperate that any plan that stopped the high inflation and could bring some level of stability to the economy was bound to be popular, at least for a while.

It is of course also not to be ignored the fact that market oriented reforms came more or less at the same time all over the world as a result of a global trend. The timing, of course, is not unrelated to the collapse of the iron curtain and the fall of the Soviet Union. This event was a global politico-economical signal just too strong to be interpreted in different ways: capitalism was more successful that communism. But as this signals fades, our proposed mechanism restarts to play a significant role in the formation of public opinion. If the reforms in a country do not bring a long, self-sustained period of wealth increasing for the majority of the people, or if a crisis develops as the one suffered in Argentina after 1998, and if people find self-serving to believe that the cause of the crisis are the corrupt politicians or that the "model" is just wrong, they will believe so whether this is true or not.

Now, going back to the evidence about the evolution of public opinion that we aim to explain, under the result that, given recent history Argentineans had political beliefs at odds with capitalist principles, the same cognitive mechanisms at work producing confirmatory bias and self-serving biases in judgments of fairness are at work here when interpreting politico economical events. Let's remember some of them form the Section 2: Lord, Ross, and Lepper ${ }^{2}$ described some underlying mechanisms responsible for such propensities:

...there is considerable evidence that people tend to interpret subsequent evidence so as to maintain their initial beliefs. The biased assimilation process underlying this effect may include the propensity to remember the strengths of confirming evidence but the weaknesses of disconfirming evidence, to judge confirming evidence as relevant

\footnotetext{
28 "Síganme, no los voy a defraudar".

${ }^{29}$ In fact, in private conversations with a leading journalist we stated that he could not announce a change in policy, as that would reduce his chances of winning the election.
} 
and reliable but disconfirming evidence as irrelevant and unreliable, and to accept confirming evidence at face value while scrutinizing disconfirming evidence hypercritically...

Remember that in their paper the authors found strong evidence for the polarization hypothesis: providing the same ambiguous information to people who differ in their initial beliefs (in their case on capital punishment) can move their beliefs farther apart.

In their papers about self-serving bias in judgments of fairness with the tort case in Texas, Linda Babcock and George Loewenstein, as we saw earlier, found a completely different result when the participants knew their role would be that of defendant or plaintiff before reading the case than, in comparison to when the participants read the case before knowing their future roles. This result, consistent with previous research in self-serving bias, suggests that the bias results from selective information processing.

What we are suggesting that the same phenomenon of selective information processing takes place when citizens process the political information that they receive after the launch of a reform process. If the view of the world (shaped by whast so far was self-serving) goes against capitalist principles, people will selectively focus on negative development, that eventually justify a negative view of what it was a supposedly successful economic program. This is natural to any complex politico-socio-economical process. In the Argentinean case there were several developments that played that role. The increase of unemployment, the increased prices of some privatized services, the relatively massive outlays of formerly public sector employees in the privatized companies, corruption, the lack of parameters to gauge whether the returns obtained by these companies was appropriate or not, or whether what had been paid for acquiring the companies was sufficient or not, were just some of them.

We asked before: since the reform process, as any real-world process, have many angles from where to look at them, what angles are going to be blessed by the public focus? Is the public going to be "impartial" when judging these processes? The answer is that the angles that are going to be the focus of the public are probably the ones that confirm the world view of the society, and it is not to be expected that that the public is going to be impartial when judging these processes because they will process differently confirming and disconfirming evidence (and they will do so unconsciously as the psychological research shows).

If our mechanism about the worldview likely to be prevalent in a given society is correct, then great difficulties are to be expected in the long run stability of pro-market capitalist reforms in an underdeveloped society. This is because on the one hand material progress is known to emerge only with capitalists rules of the game, but on the other, these rules may be at odds with the self-serving worldview that tends to be popular in underdeveloped societies. The progress toward capitalism has to be accompanied of a change in such worldview, with breaking through this cultural or cognitive barrier. Otherwise, sooner or later such view will emerge and will probably resist the reform process. 
Also, research on self-serving assessments of fairness suggests that these assessments are likely to occur in morally ambiguous settings in which there are competing "focal points" that is, settlements that could plausibly be viewed as fair ${ }^{30}$. Using the words of Babcock and Loewenstein ${ }^{17}$, self-serving assessments of fairness enters whenever there is some sort of asymmetry. But by this we do not mean asymmetry of information. As we saw, in the experiments above the two parts to a dispute had exactly the same information. The asymmetry refers to the fact that the situation does not have to be perfectly symmetric so that there is only one natural criterion for fairness. For example, few subjects placed in a symmetric bargaining situation to split $\$ 10$ will believe that anything other that an even split is fair. But as soon as minimal asymmetries are introduced, fairness criteria tend to bend toward self-serving. For example, if the result of non-agreements to split the above $\$ 10$ between the two parties result in asymmetric payoffs (for example, one player gets $\$ 2$ and the other gets $\$ 4$ ), then automatically two criteria of fairness emerge. A $\$ 5-\$ 5$, even split of the $\$ 10$ and a $\$ 6-\$ 4$ split which divides equally the marginal $\$ 4$. Of course, selfserving assessments of fairness predicts that the player that under non-agreement gets $\$ 2$ will defend the $\$ 5$ - $\$ 5$ even split, while the other player will defend the $\$ 6-\$ 4$ split.

Unfortunately, again, almost all important political discussions are of this sort. In fact, real life experience and real history almost always contain the kind of ambiguous information and competing claims that are breeding grounds for self-serving assessment of fairness. Needless to say, so is information coming from a reform that changed the way the country had been operating for the last fifty years.

It is then perfectly consistent with these cognitive biases that people will turn against a successful reform process if the principles of these reforms are at odds with the self serving view of the world of the people. In a sense what we are saying is that in order to be really successful a reform not only has to provide an increase in the material well being of the society but also in its cognitive well being. And for that there has to be no contradiction between the mechanisms that generate material well being and progress and the view of the world of such society.

We also asked: are the preferences of people completely captured by the theory of reveled preferences? Or are there also other aspects of public opinion relevant for understanding complex political processes?

The key point to answer these questions is to realize that the processing of political information always requires a criterion. And it is probably a true statement that given any two sentences $\mathrm{A}$ and $\mathrm{B}$, there is always a criterion that makes $\mathrm{A}$ compatible with $\mathrm{B}$ unless B is "no A". For example, how can it be that the same people that were critics of the hypermarkets or of the privatized companies, at the same time decided to consume more than ever before of their products? The people may very well feel that they are in a sort of prisoners dilemma type situation, in which while these companies are bad for the country, given the rules of the game they have no choice but being their customers. In fact, informal conversations suggest that something of this sort is going on in many people's mind.

30 "Strategy of Conflict", by Schelling, T., Cambridge: Harvard University Press, 1960. 
Note then that a straightforward application of the theory of revealed preference may not give the right intuition as of what is going on in people's minds. As we said before, if we were to apply the theory of revealed preference we would probably disregard these answers as just "cheap talk", except for the fact that we know that politicians do keep an eye on the preferences of the voters and decide policies at least partly based on them.

We insist then on the fact that the hypotheses that we have used to explain the empirical evidence about public opinion and answer the questions we posed are simply our theory about the worldview to be expected in given society and universal cognitive mechanisms that are completely accepted in the psychological as well as behavioral economics literature. This work explored the consequences for political processes, and reforms processes in particular, of the psychology of universal cognitive biases.

These systematic biases raise doubts about the ability of underdeveloped societies to replicate the rules of the games of developed economies. Such convergence will take place only if societies can learn in any meaningful way the basic ingredients necessary for prosperity, and accept to organize themselves accordingly. The problem is that there are many possible theories to interpret the data that some societies are developed and many others are not, and there are also many possible theories about why some people progress and some others do not. Unfortunately, as we have seen, self-serving bias suggests that the theories that are likely to be adopted by a majority of people in an underdeveloped society are not the ones that lead to a learning process convergent towards prosperity.

\section{A reflexion on policy implications}

Our analysis has some direct implications for reform implementation. The first, is that one should be aware of the need to communicate appropriately the need, objectives and implications of the reform process. This, of course, is easily said but not so easily done. However, our discussion points to the need to sell and convince as major ingredients of a reform package.

Similarly, if people tend to absorve information selectively, it is important to curtail the development of focal points, that may rally public opinion against the reform process. In the case of Argentina, the emergence of high unemployment called for dramatic measures that could convince the population that this problem was taken care of.

Finally, a focal point or a societal objective may be necessary. Italy and Spain consolidated their reform process as a result of their hope and ambition to become active members of the european community. Politicians and political science literature has devoted many pages to how politicians build a "vision for a country" that can align public opinion preferences. Our research suggests that, far from irrelevant, developing these views is key to a succesful implementation of the reform process. 